\title{
Growth of Colloidal Nano-particles: New Biomaterials
}

\author{
S Abdalla* \\ Physics Department, Faculty of Science, King Abdulaziz University at Jeddah, Saudi Arabia
}

To get new materials, scientists can simply take inspiration from nature, for example to try to emulate the myriad configuration of materials using artificial methods. New materials, in particular, biomaterials, have emerged from such "bio-mimicry" including technologies that have strong and well established structures such as the close-packed honey-comb structures: Polymer resins that try their best to be wooden and yet others that seek to copy the unbelievable strength to weight ratio of fluffy fibers like cotton, spider silk, and bird bone (or bone as general). Every inspiration from nature makes certain sense. However, there are some scientists, on the contrary, do not favorite to emulate nature in anything but they adopt nature's processes to profiteer biomaterials; to either allow natural systems to generate such materials in their pure state in situ and then use these biomaterials with limited synthetic mediation. A genetically modified canola (Brassica rapa) might produce an artificial polymer [1], for instance, or microbes fermented to stretch out fiber faster than the slickest of silk worms. Scaffolds for surgical repair, tissue engineering, and wound healing, for instance, might be grown, perhaps as hybrid biomaterial, but mostly without the need to emulate nature. Moreover, there are many examples that used in medical areas such as diagnostics, treatment, and experimental surgical techniques in the form of materials for prosthetics. Thanks to bio-materials, the notation of an "all-natural heart" or kidney is no longer a concept from far future science fiction but is something that is well within our comprehension. Moreover, Marine organisms are being modified and hybridized to create biomaterials that are certainly more than mimics; they are nature in the lab exemplified. Self-assembly from specific mixture of integrands of natural scale are simply a key to success and demand insight to produce artificial nature rather than natural effect. For example colloidal nano particle growth in liquids follows the mechanism of either addition of monomers to the present Nano-Particles (NPs) or cohesion of the existing NPs $[2,3]$. With respect to the cohesion of NPs, the details regarding the attachment and fusion between NPs have not sufficiently been investigated. The growth of crystals through the coalescence and aggregation of NPs is now widely known in bio-mimetic [4,5], biomineral [2,3], and natural systems [6]. The resulting- material (crystals) shows complex structures varying from one dimensional chain up to three dimensions array. So far the final structure diffracts as a single crystal, embodiment that the primary NPs aligned during initial outgrowth [7] and oriented attachments occurs when coalescence is synchronized and accompanied by co-alignment [8]. However, the track by which oriented attachments occurs has not been effectively known. Moreover, if the primary NPs align before attachment, the dynamics of that procedure and in particular the forces that derive it have yet to be known. Some published works have inferred that oriented attachment is important in the initial crystal growth of biomaterials NPs [9], which are abundant and essential materials in biogeochemical processes that form the surface of Earth and its environments [10]. Low-resolution Transmission Electron Microscope TEM images show [11] that the NPs grow both through monomer addition from solution and particle attachment events. In figures 1-4, one can see that the particles are contacting one another until attachment finally occurred in a period about 800 seconds. The surfaces of two adjoining particles made transient contact at several points and orientations before finally attaching and growing with each other. One can notice from figure 1 that, beginning at the contact point, atoms try to fill the interface-region in a period of time from some seconds up to some tens of seconds (10 seconds $<$ time $<100$ seconds). Here, contamination or production of defects in the crystal will appear if interface would be eliminated (Figure 2). Reduction of boundary energy will result in periodic matching of the Bravais lattice which relates the boundary energy to the density of coincident sites. Here, one can show that after the above mentioned TEM images, the speed of moving particles can be detected: For example, in figure 3 the smaller particle diffuses with a speed $0.7-0.8 \mathrm{~nm} / \mathrm{s}$ because it passes a distance from $1.4 \mathrm{~nm}$ to 1.6 $\mathrm{nm}$ before attachment in 0.5 seconds after about $83 \mathrm{~s}$ from the initial process. Consequently, the rate of growth of particles can be deduced when one takes several TEM images as a function of time. Figure 4 shows that the growth rate decreases through the first two seconds (from $13 \mathrm{~nm} / \mathrm{s}$ down to $0.14 \mathrm{~nm} / \mathrm{s}$ ) [12].

This is followed by a constant growth rate $0.034 \mathrm{~nm} / \mathrm{s}$ when time

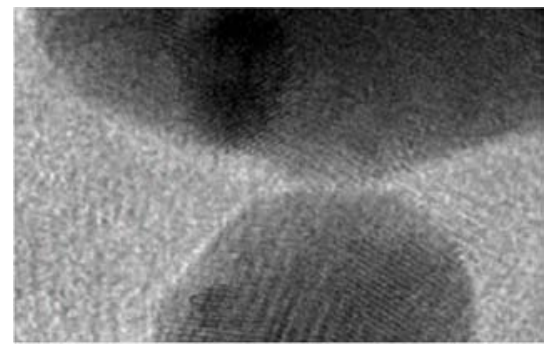

Figure 1: Initial contact at zero time: $\mathrm{t}=0$ seconds.

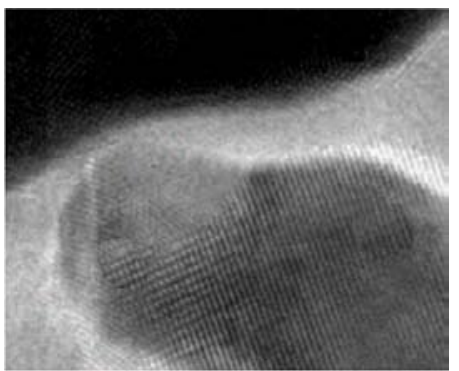

Figure 2: Particle tends to approach from the bulk and tends to get more contact surface at time: $t=82$ seconds.

${ }^{*}$ Corresponding author: S Abdalla, Physics Department, Faculty of Science, King Abdulaziz University at Jeddah, Saudi Arabia, Tel: 00966-6964227; Fax: +966 6951106; E-mail: soulimanabd@hotmail.com

Received November 12, 2012; Accepted November 15, 2012; Published November 23, 2012

Citation: Abdalla S (2013) Growth of Colloidal Nano-particles: New Biomaterials J Material Sci Eng 2: e107. doi:10.4172/2169-0022.1000e107

Copyright: () 2013 Abdalla S. This is an open-access article distributed under the terms of the Creative Commons Attribution License, which permits unrestricted use, distribution, and reproduction in any medium, provided the original author and source are credited. 


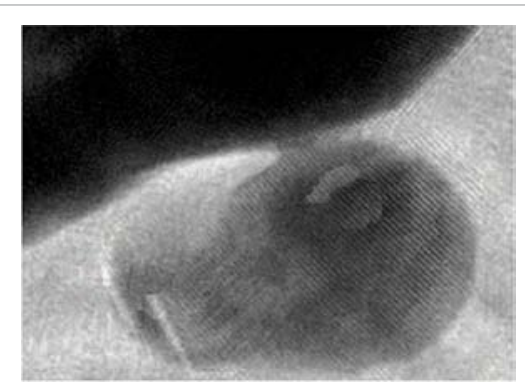

Figure 3: Particle start to bind the bulk at time: $t=145$ seconds (binding contact area is about $10 \mathrm{~nm} \times 10 \mathrm{~nm}$ ).

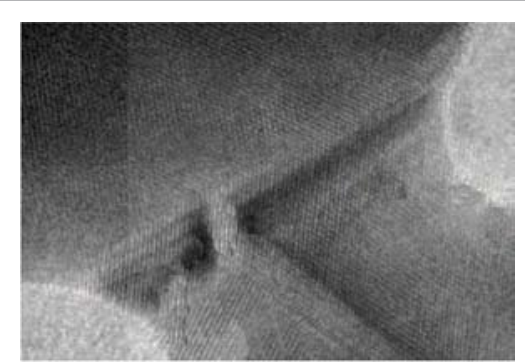

Figure 4: Particle binds totally to the bulk at time: $t=780$ seconds (binding contact area is about $50 \mathrm{~nm} \times 50 \mathrm{~nm}$ ).

reaches high values (20 seconds). Takahashi et al. [13], has shown that the chemical potential affects the interface curvature and as a consequence the speed of growth is affected. However, the misaligned particles behavior can be explained in the light of production of induced grain boundary migration, through which the energy stored in dislocations and point defects at the grain boundary of a highly strained nano particles enhances re-crystallization [14]. On the other hand, from the curvature dependence of the free energy, the dissolution rate increases as particle size decreases. NPs explored several configurations before attachment can happen because the primary NPs tend to aggregate into clusters where they interacted in close in situ for sufficient periods of time to become nearly aligned through Brownian motion. Forces of long-range attractive type are necessary to keep NPs in close to each other while osmotic forces play an essential role and they stabilize to large extent the colloidal forces; however, this colloidal stabilization must be sufficiently weak to allow the NPs to approach each other within the primary minimum of the interaction potential. From equilibrium point of view, the NPs tend to be separated by distances in the nanometer scale until a correct configuration is reached implies the existence of a slight energetic barrier which stands with the initial explanation about electrostatic interactions.

\section{References}

1. Akiyama H, Makiyama D, Nakamura K, Sasaki N, Minegishi Y, et al. (2010) A novel detection system for the genetically modified canola (Brassica rapa) line RT73. Anal Chem 82: 9909-9916.

2. Chakrabarti R, Schweizer KS (2010) Polymer-mediated spatial organization of nanoparticles in dense melts: Transferability and an effective one-component approach. J Chem Phys 133: 144905-144917.

3. Killian CE, Metzler RA, Gong YUT, Olson IC, Aizenberg J, et al. (2009) Mechanism of Calcite Co-Orientation in the Sea Urchin Tooth. J Am Chem Soc 131: 18404-18409.

4. Colfen H, Antonietti M (2005) Mesocrystals: inorganic superstructures made by highly parallel crystallization and controlled alignment. Angew Chem Int Ed Engl 44: 5576-5591.

5. Colfen H, Antonietti M (2008) Mesocrystals and Nonclassical Crystallization. Wiley, USA.

6. Alivisatos AP (2000) Naturally Aligned Nanocrystals. Science 289: 736-737.

7. Song J, Saiz E, Bertozzi CR (2003) A new approach to mineralization of biocompatible hydrogel scaffolds: an efficient process toward 3-dimensional bonelike composites. J Am Chem Soc 125: 1236-1243.

8. Moreira ML, Andres J, Mastelaro VR, Varela JA, Longo E (2011) On the reversed crystal growth of $\mathrm{BaZrO}_{3}$ decaoctahedron: shape evolution and mechanism. Cryst Eng Comm 13: 5818-5824.

9. Wheeler DA, Wang G, Ling Y, Li Y, Zhang JZ (2012) Nanostructured hematite: synthesis, characterization, charge carrier dynamics, and photoelectrochemical properties. Energy Environ Sci 5: 6682-6702.

10. Penn RL, Zhu C, Xu H, Veblen DR (2001) Iron oxide coatings on sand grains from the Atlantic coastal plain: High-resolution transmission electron microscopy characterization. Geology 29: 843.

11. Koriaa P, Yagia H, Kitagawae Y, Megeeda Z, Nahmias $Y$, et al. (2010) Selfassembling elastin-like peptides growth factor chimeric nanoparticles for the treatment of chronic wounds. PNAS 108: 1034-1039.

12. Wang Z, Wang F, Peng $Y$, Zheng Z, Han $Y$ (2012) Imaging the Homogeneous Nucleation During the Melting of Superheated Colloidal Crystals. Science 338: 87-90.

13. Takahashi K, Limmer SJ, Wang Y, Cao G (2005) Growth and Electrochemical Properties of Single-Crystalline $\mathrm{V}_{2} \mathrm{O}_{5}$ Nanorod Arrays. Jpn J Appl Phys 44: 662668.

14. Deng HX, Grunder S, Cordova KE, Valente C, Furukawa H, et al. (2012) LargePore Apertures in a Series of Metal-Organic Frameworks. Science 336: 10181023. 